\title{
“Feline” esophagus
}

\section{David J. DiSantis, ${ }^{1}$ Raymond B. Dyer ${ }^{2}$}

${ }^{1}$ Department of Radiology, Chandler/UK Medical Center, College of Medicine, University of Kentucky, Room HX-315A, 800 Rose Street, Lexington, KY 40536, USA

${ }^{2}$ Department of Radiology, Wake Forest Baptist Medical Center, School of Medicine, Wake Forest University, Medical Center Blvd., Winston-Salem, NC 27157, USA

While a feline might conceivably mimic a human esophagus (Fig. 1), the human esophagus likewise can mimic a feline's. Fine transverse esophageal folds, a normal finding in a cat's distal esophagus [1], sometimes appear transiently on double-contrast barium esophagography in humans (Fig. 2) [2].

Termed an esophageal "shiver" because of their evanescence, the circumferential plications have been attributed to contraction of the muscularis mucosae [2, 3]. The feline esophagus appearance at esophagography has a strong association with gastroesophageal reflux [2].

Differential diagnoses for feline esophagus include the stacked-ring appearance of eosinophilic esophagitis and the fixed transverse folds that can signify scarring from reflux esophagitis [2].

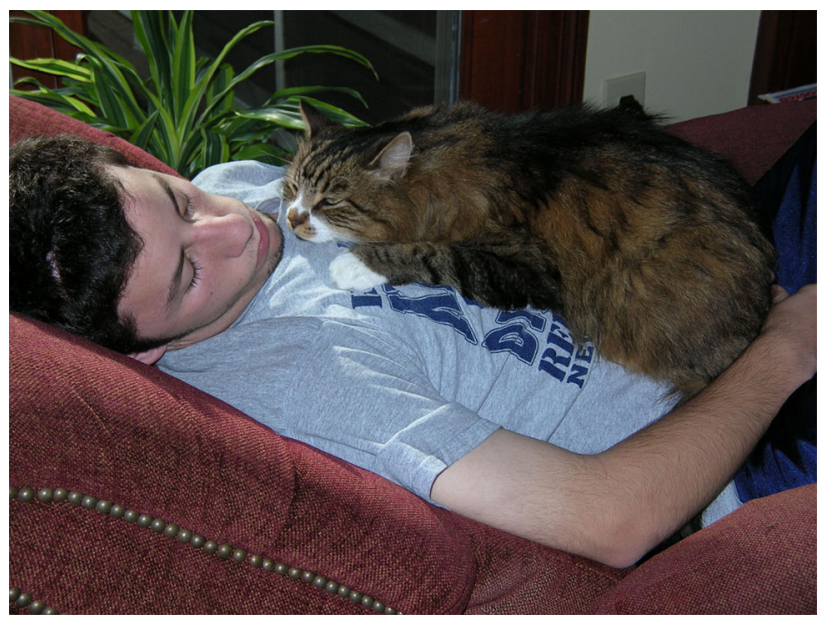

Fig. 1. Feline "Willie" demonstrates the orientation of the esophagus in this supine human (image used with permission of Richard T. Dyer).

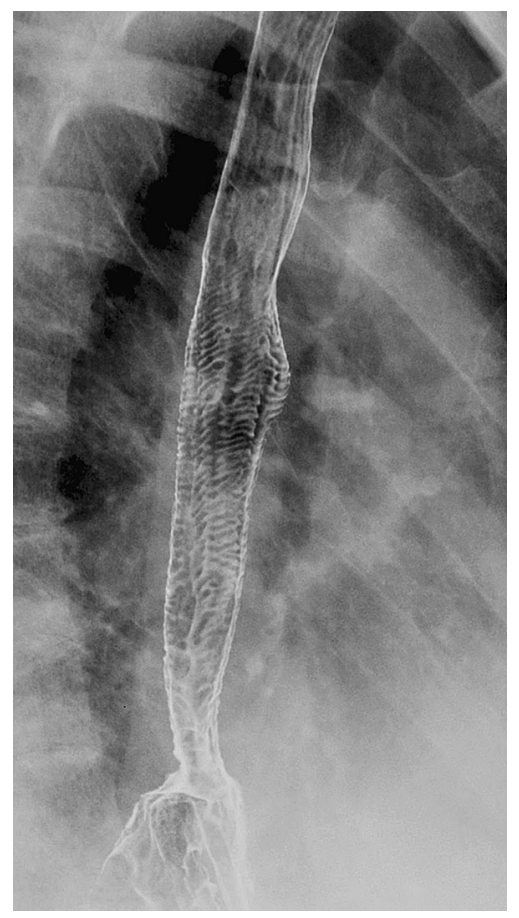

Fig. 2. "Feline" esophagus on barium study. Double-contrast esophagogram depicts transverse esophageal folds. Lumen contour subsequently normalized within seconds. Note the sliding-type hiatal hernia in this patient being evaluated for symptoms of gastroesophageal reflux.

\section{References}

1. Goldberg HI, Dodds WJ, Jenis JH (1970) Experimental esophagitis: roentgenographic findings after insufflation of tantalum powder. AJR 110:288-294.

2. Samadi F, Levine MS, Rubesin SE, Katzka DA, Laufer I (2010) Feline esophagus and gastroesophageal reflux. AJR 194:972-976.

3. Furth EE, Rubesin SE, Rose D (1995) Feline esophagus. AJR 164:900

Correspondence to: David J. DiSantis; email: ddi226@uky.edu 